\title{
From Feedback Seeking to Psychological Attachment, the Mediating Role of Adaptive Performance in Perceived Obstruction Context
}

\author{
Guillaume R. M. Déprez ${ }^{1}$, Nicolas Bazine ${ }^{1}$, Léa Fréour ${ }^{1}$, Marco Peña-Jimenez ${ }^{1}$, Nicola \\ Cangialosi $^{2}$, and Adalgisa Battistelli ${ }^{1}$ \\ ${ }^{1}$ Université de Bordeaux (France), ${ }^{2}$ Università degli Studi di Firenze (Italy)
}

\author{
Corresponding author: $\quad$ Guillaume R. M. Déprez \\ Université de Bordeaux, Laboratoire de Psychologie EA4139 \\ 3ter place de la Victoire, 33000 Bordeaux, France \\ Email: guillaume.deprez@u-bordeaux.fr \\ ORCID: 0000-0003-1554-6105
}

Conflicts of Interest: None. Funding Statement: This research received no specific grant from any funding agency, commercial or not-for-profit sectors.

\section{PLEASE CITE AS:}

Déprez, G., Bazine, N., Fréour, L., Peña-Jimenez, M., Cangialosi, N., \& Battistelli, A. (2021). From Feedback Seeking to Psychological Attachment, the Mediating Role of Adaptive Performance in Perceived Obstruction Context. The Spanish Journal of Psychology, 24, E1. https://doi.org/10.1017/SJP.2021.1

The original article can be found at: https://doi.org/10.1017/SJP.2021.1 
Abstract

Based on proactivity literature, feedback seeking behavior is generally used throughout an individual's career to enable better adaptation to the work environment. However, it has recently been shown that declining levels of feedback seeking behavior may result in decreased psychological attachment over time. This study aims to explore whether individual adaptivity represents a mechanism through which feed-back seeking affects psychological attachment (i.e., well-being involvement and withdrawal). In addition, the interaction effect of organizational obstruction between individual adaptivity and psychological attachment was examined. Based on three-wave survey data obtained from 273 participants from French organizations, a moderated mediation model was tested using structural equation modeling. Results confirmed that adaptive performance mediated positively the relationship between feedback-seeking and well-being involvement and negatively with withdrawal. Moreover, perceived organizational obstruction moderated negatively the relationship between adaptive performance and withdrawal, and positively that with well-being. These results shed new light on the relationship between proactivity (i.e., feedback seeking behavior) and adaptive performance, but also on the positive short-term contribution of successful adaptation in a perceived obstructive organizational context. Theoretical contributions and practical implications for human resource management are discussed.

Keywords: adaptive performance, feedback-seeking, perceived organizational obstruction, proactivity, psychological attachment 
« Am I doing well? » is a natural question one can ask to reassure himself/herself regarding his/her actions (Anseel et al., 2015). Thus, workers seek feedback to answer this common question in their daily routine. Feedback-seeking behavior (FSB) refers to "the conscious devotion of effort toward determining the correctness and adequacy of behavior for attaining valued end states" (Ashford 1986, p. 466). Feedback is pertinent information that provides cues to improve (Ashford et al., 2016). Employees who actively seek feedback about their everyday activities tend to perform better (Gong et al., 2017) and adapt to their work environment (Ashford et al., 2016).

According to the organizational socialization (Morrison, 1993) and proactivity literature (Grant \& Ashford, 2008), individuals seek feedback because it constitutes a means to obtain accurate information and helps them to survive and prosper in the organization (Ashford \& Cummings, 1983). FSB is a proactive behavior (e.g., Ashford \& Cummings, 1983; Ashford et al., 2003; Crant, 2000) that helps workers to fit organizational norms and demands (e.g., Ashford, 1986; Morrison, 1993). Moreover, FSB has shown its importance to develop performance at work because it helps to clarify one's role (Whitaker et al., 2007) and to adjust one's behavior (Tsui et al., 1995).

As a result, FSB's proactive nature is particularly relevant for organizations because it can support employees' continuous adaptation, learning and performance throughout their career (Crant, 2000; Crommelinck \& Anseel, 2013). FSB should thus allow individuals to adapt to ambiguous, changing and/or uncertain organizational contexts. The view that employees proactively seek feedback to better adapt to their environment is consistent with self-regulation theories (Bandura, 2001; Locke \& Latham, 2006) that emphasize the capacity of individuals to direct their own actions and performance towards their goals by setting their own expectations and by monitoring their progress towards those expectations (Vohs \& Baumeister, 2004). 
However, no consensus exists in the literature about the relationship between adaptability and proactivity (Ellis et al., 2015; Zhu et al., 2014). Adaptability and proactivity are essential to organizational performance, but they are conceptualized as opposite (Frese \& Fay, 2001), independent (Griffin et al., 2007), or interrelated constructs (Berg et al., 2010). It is still difficult to determine how these constructs are connected and how they influence each other. Unfortunately, few studies have addressed this issue (Zhu et al., 2014) and fewer investigated the empirical relationship between FSB and individual adaptivity. Our research follows the perspective raised by Berg et al. (2010) by proposing that proactivity (i.e., FSB) could foster adaptivity (i.e., individual adaptive performance), stating that in order to meet their own work expectations, employees must seek to adapt to their environment by using self-regulatory tactics such as feedback (Ashford \& Tsui, 1991).

Succeeding to be in line with the team or organizational standard through a selfregulated approach should in the long run allow individuals to be more involved in their organization (Park \& Park, 2019). However, there have been few attempts to examine the relationship between feedback and psychological attachment. Vandenberghe et al. (2019) have shown that lower levels of FSB can lead to a decrease in organizational commitment over time and then a greater turnover likelihood. These results would be linked to employees' failure to commit and adapt to the environment. Adaptive performance would thus play a key role in the psychological attachment (Gruman \& Saks, 2013) and well-being processes (Cooper-Thomas et al., 2014). Furthermore, it has been found that contextual variables can limit or enhance the effect of individuals performance (e.g., Griffin et al., 2010). Employees who lack the capacity to self-regulate in obstructing and unpredictable environments would be less involved in their work and less likely to adapt to unexpected events (Pulakos et al., 2000). Notwithstanding that, Jundt et al., (2015) highlighted that there has been a limited amount of contextual research in the adaptive performance literature and called for more studies 
examining its relevance. Adaptive performance generated by self-regulated tactics (e.g., feedback seeking) is likely to be useful in situations where one perceives the organization as a source of obstruction. Indeed, this kind of workplace requires high adjustment capacity because it may hinder one's well-being (Gibney et al., 2009) and enhance withdrawal (Walsh et al., 1985). Pulakos et al. (2000) support this premise because well-adapted employees can find new resources beyond the formal solutions, solve problems creatively and then more commit to organizations.

Based on self-regulation theories, the contribution of our study is threefold. First, it investigates the positive relationship between proactivity and adaptivity beyond the organizational socialization context (Chan \& Schmitt, 2000). Because the adaptation process is not limited to the organizational entry, it is worthwhile to extend this research to other periods in the organizational course. In doing so, we contribute to Zhu and colleagues (2014) appeal for more empirical evidence to assess the validity of each view of the relationship between proactivity and adaptability. Secondly, our research examines the extent that adaptive performance helps to develop well-being at work and reduces withdrawal (Jundt et al., 2015). Our study thus provides clues on the benefits of implementing an adaptive approach following proactive action. Thirdly, our study explores the effect of perceived organizational obstruction (POO) on the individual adaptive process. We made the case that POO had a direct negative impact on psychological attachment variables. However, its effects were reversed when individuals used FSB to better adapt to a context of perceived obstruction. In sum, we extend the literature of FSB (Ashford et al., 2016) by exploring its role in shaping adaptive performance (Park \& Park, 2019) and by investigating the role of adaptive performance between FSB and adaptive process outcomes (i.e., well-being, withdrawal) in POO context.

\section{Theoretical Background and Hypothesis}




\section{Impact of the Feedback Seeking on Individual Adaptivity}

FSB refers to individuals actively monitoring and seeking information for organizationally determined and individually held goals (Ashford \& Cummings, 1983). The FSB literature has flourished with the organizational socialization literature, as the period of entry in an organization is very important to adjust to the organizational requirements and to become a competent employee (Bauer et al., 2007). Indeed, joining a new organization is a period of trouble, uncertainty, and doubt (Griffeth et al., 1999). Considering the above, developing knowledge, rules and skills is an effective way to adjust to the workplace (Kammeyer-Mueller \& Wanberg, 2003). This can be achieved either with organizational or socialization tactics initiated by proactive worker, particularly by using FSB (Chan \& Schmitt, 2000). However, FSB are tactics deploy by workers to learn and to develop competencies not only during the socialization phase but also during their whole career (Ashford et al., 2003).

Since the first conceptualization of FSB (Ashford \& Cummings, 1983), two dimensions have been identified, inquiry and monitoring. Inquiry happens when directly asking others, whereas monitoring describes an indirect strategy to attain feedback (Ashford et al., 2003). Monitoring consists of observing the environment and others to find meaningful cues which can provide information. From a conceptual point of view, literature has considered FSB as a single general concept (Morrison, 2002). However, several studies challenged this perspective underlining that inquiry and monitoring are different dimensions (Anseel et al., 2015; Ashford, 1986). Anseel et al. (2015) found that these two constructs were related but distinguishable from each other, accordingly they argued that FSB would be a multidimensional construct (Ashford \& Cummings, 1983). Moreover, there is consensus on the proactive nature of the FSB in the workplace (Grant \& Ashford, 2008; Parker \& Collins, 2010). This assumption postulates that employees do not wait to receive information from 
others but rather proactively seek information or evaluations about their work, performance or duties (Ashford \& Cummings, 1983). The latter implies that FSB, as other proactive constructs, is self-starting, change- and future-oriented (Crant, 2000; Tornau \& Frese, 2013). Furthermore, proactivity is also associated with taking risk which can damage the image of the worker (Ashford \& Cummings, 1983). For instance, inquiry is an acknowledging act of one's ignorance which can be interpreted as a sign of incompetence (Ashford et al., 2003). Thus, FSB is a costly behavior and is often used sparingly.

The literature of FSB strove to determine its nature and when and why workers used it (Ashford et al., 2016; De Stobbeleir et al., 2019) by reviewing individual antecedents (e.g., cognitive style, demographic variables), relational antecedents (e.g., quality of the leadersubordinate relationship) and organizational antecedents (e.g., organizational structure). Beyond the literature of organizational socialization, research on FSB had studied particularly the relation with one outcome: The job performance. The relationship between FSB and performance was never direct. It was mediated by several variables like personality traits (VandeWalle \& Cummings, 1997), contextual factors (Krasman, 2011) and the quality of the feedback (Lam et al., 2017). The association could also depend on moderators like the type of FSB (i.e., negative vs. positive) or goal orientation (Gong et al., 2017).

Ashford et al., (2016) emphasized that the FSB behavior was like a valuable resource or strategy which brings to the attention of the employee areas of improvement and leads to an increase of performance (Ashford, 1986). Thus, FSB is a self-regulatory behavior by which one acquires accurate information about his/her actions and offers guidance to know how to adjust one's actions (Ashford et al., 2003). In this study, we focused on FSB as a behavioral strategy to develop employee adaptivity. The employees would seek feedback to cope with changes at work (Cangialosi et al., 2020; Pulakos et al., 2000) and to protect their image and ego from negative feedback that their colleagues or supervisor might give (Moss et al., 2003). 
Between the two dimensions of FSB, only the inquiry has been shown to be related to job performance (Anseel et al., 2015). Accordingly, in this study we focused on the inquiry strategy.

\section{Importance of Individual Adaptivity}

Literature highlighted the importance of adaptation to cope with the changes in the work environment (Baard et al., 2014; Griffin et al., 2007; Pulakos et al., 2000). Baard et al. (2014) propose a multi-level conceptual architecture that allows to "situate theoretical and research treatments of adaptation across the organizational space" (p. 89). Indeed, adaptation is a broad, multi-dimensional concept that can be applied at all organizational levels. Adaptation is composed of four different approaches (performance construction, individual difference, performance change, and process) that bring together different conceptualizations. For example, adaptability is generally conceptualized as a meta-competence or a set of traits, skills or knowledge that provide one with the key to effectiveness in changing work conditions (Chan \& Schmitt, 2000), while adaptivity can represent behaviors that focus on how one copes with, responds to, and supports change (Griffin et al., 2007). In this paper, the focus is on adaptivity perspective.

Adaptivity is useful for dealing with uncertainty and showing autonomy at work (Bindl \& Parker, 2010). In an ever-changing environment, it is valuable to identify behaviors that allow employees to fulfill their tasks and contribute to the effectiveness of the group and the organization (Griffin et al., 2010). It is even more valuable to know the behaviors that sustain employee performance. To this end, measures of adaptive performance have been developed to respond to these demands of work context (Pulakos et al., 2000). Scholars have generally considered adaptive performance as a facet of the overall performance which is distinct from task and contextual performance (Han \& Williams, 2008; Pulakos et al., 2000). In this framework, certain forms of work performance are more beneficial than others 
particularly when the workplace demands to learn new ways to perform tasks (Pulakos et al., 2000). Based on work performance theories, Griffin et al. (2007) described three different forms (i.e. adaptive, proficiency, proactive). While proficiency represents task performance, change behaviors, which include adaptivity and proactivity, describe behaviors when the work requirements cannot be clearly anticipated (Grant \& Ashford, 2008; Griffin et al., 2010). Proactivity defines self-initiated change behaviors to actively change the self, the workplace or the environment, whereas adaptivity refers to successfully accommodating the uncertainties of externally initiated changes (Griffin et al., 2007).

To evaluate adaptivity, in this study, we focus on adaptive behaviors which Griffin et al. (2007) defined as adaptive performance, as the degree to which individuals cope with, respond to, and/or support changes resulting in more effective contribution in their role as individuals, team members, or as members of the organization. Previous scholars have mainly focused on the dispositional factors which enhance adaptive performance. For instance, general and specific cognitive abilities have been reported to have a positive influence on adaptability (Kozlowski et al., 2001). Particularly, traits of the big five such as openness to experience, emotional stability, conscientiousness but also self-efficacy, coping style and goal orientation display a positive link with adaptability (Kozlowski et al., 2001). However, some studies attempted to understand how to enhance adaptive actions outside the scope of the study of dispositional factors (Jundt et al., 2015). Research showed that stakeholders demonstrate adaptive behaviors when they were able to master their environment (Chan \& Schmitt, 2000; Park \& Park, 2019). Therefore, the use of environmental resources allows employees to respond to new work demands (Ghitulescu, 2013). FSB capture particular proactive behaviors that occur in a limited domain and that are conceptualized as active behaviors (Crant, 2000), whereas adaptivity supposes a passive perspective (Griffin et al., 2007) that allow people to adapt or cope with the uncertain environment (Pulakos et al., 
2000). The active use of proactivity via FSB, initially, should then allow the individual to develop over the long term automation of passive responses adapted to his environment, thus allowing him to develop a feeling of personal control (Ashford \& Black, 1996; Crant, 2000) and to reduces the psychological cost related to proactivity (Ashford \& Cummings, 1983). Although adaptivity can be conceptualized as opposed to proactivity, they would no longer be opposed but complementary over time (Berg et al., 2010). Then, employees can be reassured about what they are doing or can gain indications to adjust their behavior in a more effective way (Griffin et al., 2010). Thus, FSB may help employees to recognize which goals are valued and rewarded by their organization (Ashford et al., 2003). Furthermore, Tsui et al. (1995) have highlighted that FSB fostered the adaptation. These propositions are congruent with some literatures studying the relationship between proactivity and adaptivity (e.g., Gong et al., 2017; Griffin et al., 2010). Thus, FSB should help one to adjust his/her behavior to managerial demands and then to adapt to the organizational environment. The above reasoning suggests the following hypotheses

Hypothesis 1: FSB will be positively related to individual adaptivity. Adaptivity as a Way to Promote Well-being at Work

Adaptive performance in the workplace is beneficial for both the employee and the organization (Cullen et al., 2014). An adaptive workforce can contribute to organizational success by the rise of many worthy behaviors at work (Ghitulescu, 2013). Carpini et al. (2017) underlined that the study of outcomes of adaptive performance is lacking. Adjustment has been mainly seen as information acquisition and uncertainty reducing, however, moving beyond these perspectives little is known of its role on well-being (e.g., Ellis et al., 2015; Gruman \& Sacks, 2013; Cooper-Thomas et al., 2014). Nevertheless, adaptative performance is likely to raise employee well-being by the process that job stakeholders master more their environment and feel less uncertainty (Chan \& Schmitt, 2000; Cullen et al., 2014). 
Well-being is still suffering from a lack of theorizing (Dagenais-Desmarais \& Savoie, 2012) but has been conceptualized as both hedonic and eudaimonic (Ryan \& Deci, 2001). In this paper we focus on the eudaimonic approach that present well-being at work as optimal functioning, meaning and self-actualization (Ryan \& Deci, 2001). Dagenais-Desmarais and Savoie (2012) argue that well-being at work represents all aspects of work life. They propose a framework which encompasses and clarifies the notion of well-being at work using five components: Interpersonal fit, thriving, feeling of competence, perceived recognition and desire for involvement. In this study, we focus on the desire for involvement, which by its nature linked to the engagement process is the only dimension of well-being that can be integrated into organizational psychological attachment theories (Dagenais-Desmarais, \& Savoie, 2012). It refers to the willingness to be involved in the organization, which is to contribute to the smooth running of the company but also to personal success (Gilbert et al., 2011). Like desire for involvement encompasses the joint effect of individual and organizational level, it is more likely to be an adaptive indicator at the workplace.

Proactive behaviors like FSB enhance employees' personal (e.g., self-efficacy), relational (e.g., social acceptance) and structural (e.g., perceived fit) resources. These resources in turn influence their appraisal process so that they approach work demands as challenges stressors rather than hindrance stressors. A well-adapted employee perceives more challenge stressors because he or she is more confident in meeting effectively work demands (Edwards, 2008). Thus, FSB enables the employee belief to achieve success and to overcome stressors (Podsakoff, LePine, \& LePine, 2007). This will in turn improve positive states at work like positive affect or commitment (Ellis et al., 2015). Moreover, positive work relationships may be a predictor of the interpersonal fit dimension of well-being at work (Dagenais-Desmarais \& Savoie, 2012). The adaptive resources acquired through FSB help the positive framing of employees' work demands. Thus, adaptivity would have a mediating role 
between FSB and well-being because the employee feels more able to perform and a greater sense of competence and social acceptance. Therefore, we propose the following:

Hypothesis 2: FSB will have a positive relationship with well-being involvement through adaptive performance.

\section{Hindrance Role of Adaptivity for Withdrawal}

Spector and Fox (2002) conceptualized withdrawal behaviors as an emotional response to environmental appraisal. Therefore, withdrawal is deemed as an employees' emotion-focused coping strategy to extract themselves from negative situations. It also ranges among the counterproductive behaviors and characterizes the lessen participation of employees in their organization (Spector et al., 2006) ${ }^{1}$. Mainly, the literature has focused on the relationship between negative mood, affect, dissatisfaction and withdrawal behaviors (Podsakoff et al., 2007). An employee who lacks adaptive performance at work has more chances to feel stress, negative emotions, cultural shift, labor management conflict, etc. However, some studies seek to demonstrate how the employee can alleviate withdrawal (e.g., Roznowski \& Hanisch, 1990). Alleviating withdrawal is critical for the organizations since counterproductive behaviors are highly costly for them (Hancock et al., 2013).

According to Griffeth et al. (1999), a well-adapted employee perceives fewer negative aspects and feels more satisfaction at work. Thus, employee adaptation is a suitable asset to offset withdrawal. When the adaptation process is effective it will likely elicit work satisfaction and will decrease the likelihood of withdrawal behavior adoption (Griffeth et al., 1999). This can be explained by the fact that adaptivity allows the employee to fulfill the requirements in terms of changes, uncertainty, novelty or unexpected events at work (Pulakos

\footnotetext{
${ }^{1}$ In this study, we concentrate only on two conceptualizations of withdrawal (i.e., lateness and absenteeism) and ignore turnover (Zimmerman et al., 2016). Some scholars support this position and consider that turnover is a single act and does not reflect a permanent withdrawal (Blau, 1985; Hanisch \& Hulin, 1990; Podsakoff et al., 2007).
} 
et al., 2000). Thus, well-adapted employees are more likely to adopt fewer withdrawal behaviors (Park \& Park, 2019).

Studies have shown that FSB also decreases withdrawal behavior at work (e.g., Ashforth et al., 2008; Ibarra \& Barbulescu, 2010) However, FSB may not participate directly to withdrawal but through a mediated way (Vandenberghe et al., 2019). Efforts to proactively build relationships and seek out information should also alleviate feelings of social separation, confusion, misfit or alienation, which can lead to work withdrawal (Kammeyer-Mueller \& Wanberg, 2003). Thus, adaptivity may play a role of mediation in the relation between FSB and withdrawal, like adaptivity helps one to form interpersonal relationships and to clarify one's role. We propose that FSB behaviors will sustain the employees' adaptation process which in turn contributes to a decrease of withdrawal behaviors.

Hypothesis 3: FSB will have a negative relationship with withdrawal behaviors through adaptive performance.

The Moderating Role of Perceived Organizational Obstruction (POO)

Studies interested in employee psychological attachment have explored the positive role that perceived organizational support can play (e.g., Marchand \& Vandenberghe, 2016). Nevertheless, perceived organizational support only captures the positive side of the organizational treatment (Gibney et al., 2009). Indeed, the organizational support theory (Eisenberger \& Stinglhamber, 2011) assumes that an absence of supportive treatment or negative treatment conduct to the same effects. However, Gibney et al., (2009) have put forward that employees distinguish between different organizational treatments. The authors conceptualized perceived organizational obstruction (POO) to examine the effects of the perception of negative organizational treatment. POO is grounded in the organizational support theory (Eisenberger \& Stinglhamber, 2011) and describes the "employees' belief that 
the organization obstructs, hinders, or interferes with the accomplishment of their goals and is a detriment to their well-being" (Gibney et al., 2009, p. 667).

Like POO is related to the employees' perceived depletion of their well-being (Gibney et al., 2009), one might intuitively think that POO will inhibit the positive effect of adaptive performance on psychological attachment. However, as adaptive performance refers to an effective reaction to situational features (Han \& Williams, 2008), an employee who performs adaptively is more likely to cope with adverse situations (e.g., environment changes).

Indeed, adaptivity requires from its champion to deal with the environment and stress at work (Pulakos et al., 2000). Beyond the strain research, the conservation resources theory postulates that people with many resources will more likely acquire additional resources (Hobfoll, 1989). Adaptivity offers the availability of several resources like positive work relationships, social support, task mastery or role clarity (Ellis et al., 2015). We suggest that even if POO can be an adverse situation that can decrease individual resources, adaptive performance following the use of FSB can have a preventive role and allow individuals to deal with POO.

Indeed, adapted employees can fill the lack of organizational resources due to POO by seeking feedback with coworkers or supervisors; peers and leaders buffering the negative effects of organizational stressors (Cohen \& Wills, 1985). Empirical research supports this hypothesis as coworkers have been shown to be a source of socioemotional, instrumental or informational support which reduces strain and perception of stressors (e.g., role conflict, role overload) and moderates their relationship (Chiaburu \& Harrison, 2008). Thus, employees will spend energy to build their social network or to learn about the organization in order to deal with POO. On the one hand, Hobfoll (1989) suggested that people who have numerous resources will more likely develop well-being. Moreover, this author proposed that seeking feedback from coworkers can foster the positive self-view and then can promote the 
employees' belief to handle difficult work situations (Hobfoll, 1989). As a result, welladapted employees facing a POO context can primarily rely on support by using FSB to foster their positive self-efficacy which in turn leads to well-being (Sonnentag, 2015). On the other one hand, Harvey et al. (2007) found that people high in affective resources less undergo the effects of negative work situations. People high in affective resources feel less job tension, less emotional exhaustion and are less willing to quit even in organizational obstruction situations. Well-adapted employees that had primarily used FSB would adopt less withdrawal behaviors and perceive even higher well-being. However, the higher the OOP, the more likely employees are to develop passive self-regulatory behaviors such as withdrawal to conserve resources (Zimmerman et al., 2016). We propose that POO enhance the relationship between adaptivity and well-being but hinder the one between adaptivity and withdrawal. We suggest the following:

Hypothesis 4: POO will moderate the positive relationship between individual adaptivity and well-being involvement such that the relationship becomes stronger at high levels of POO.

Hypothesis 5: POO will moderate the negative relationship between individual adaptivity and withdrawal such that the relationship becomes weaker at high levels of POO.

\section{$<$ Insert Figure 1 Here $>$}

\section{Method}

\section{Sample and Procedure}

We tested our hypothesized model using a three-wave survey on a random sample of French employees $(N=273)$ recruited via professional social media (i.e., Facebook, LinkedIn, Viadeo). The questionnaire was distributed to job self-help groups, job search groups and jobspecific focus groups (e.g., nurses, lawyers, handlers). The questionnaire was hosted on a private and anonymous platform (Limesurvey). A message offering to participate in the study 
provided access to it. This message also invited participants to leave a comment when they completed the questionnaire. First, this approach made it possible to thank each participant and to update the message in the discussion group pages. Previously, to participate, respondents were asked to be employed, to deal with an ongoing organizational change, and to work full-time. The sample was essentially composed of workers from health (24\%) and social $(22 \%)$ sectors. Workers from administration (20\%), high distribution (18\%), and educational $(16 \%)$ sectors also participated. The sample was $85 \%$ female with an average age of $35.10(S D=11.19)$. Most of the workers were from the public sector $(47 \%)$, had a tenure to their organizations longer than 1 year $(79.4 \%)$ and worked in team context $(89.4 \%)$. The majority of participants were employees without managerial responsibilities in their organization (63\%) and had a degree at least equivalent to bachelor $(71.8 \%)$.

We collected data at three points in time to analyze the effect across time of our hypothesized model and to reduce the potential for common method variance (Podsakoff et al., 2003). We aimed at a starting sample of 1,000 participants to Time 1 to ensure an adequate sample at Time 3. It has been shown that one-month delay recruitment ensures lower average correlations than in a cross-sectional collection context (Podsakoff et al., 2012). Yet, well-being and withdrawal are constructs that can take several weeks to emerge (Somers, 2009; Sonnentag, 2015). We, therefore, followed a recruitment procedure spaced three months apart between each collection time. The first-time recruitment was conducted using professional social network. Then respondents were contacted for Times 2 and 3 by using email addresses collected during the first time point. At Time 1, 1,097 participants reported the measure in which they seek feedback from their direct supervisor (i.e., four-item FSB scale). At Time 2 - approximatively three months after the first completion of the survey - 536 remaining participants were asked to indicate the extent to which they were adopting individual adaptive performance behavior (i.e., three-item adaptive performance scale). 
Finally, 273 participants completed the third phase, approximately three months after the second completion. Participants were asked to indicate their perception of how the organization obstructed them (i.e., five item POO scale), but also their sense of well-being at work (i.e., five-item well-being involvement scale) and the extent to which they were engaging in withdrawal behaviors (i.e., four-item withdrawal scale). An average level of dropout was observed; sample decreased approximatively by half between each point in time (Time 1 - Time 2: 52\%; Time 2 - Time 3: 49\%).

\section{Measures}

All measures were originally compiled in English; except for the well-being measurement scale, which was originally constructed and validated in French. We followed the translate-retranslate procedure to ensure a good translation of the items (Brislin, 1970). First, the items were translated in French by a bilingual collaborator. Then, items were translated back into English by a bilingual native speaker. Finally, potential discrepancies between the original and French versions were discussed within the author team. For each measure we used a Likert-type scale procedure rated from one to five.

Feedback seeking. At Time 1, feedback seeking was assessed using a four-item measure from Ashford and Black (1996). Sample items included "Sought critiques from your boss" and "Sought feedback on your performance after assignments" $(\alpha=.88 ; 1=$ very few to $5=a l o t)$

Individual task adaptivity. At Time 2, respondents provided task adaptivity selfevaluation with three items from Griffin et al. (2007). Items included "You adapted well to changes in core tasks" and "You coped with changes to the way you have to do your core tasks" $(\alpha=.67 ; 1=$ very few to $5=$ a lot $)$. 
Well-being involvement. At Time 3, well-being involvement was assessed using a fiveitem measure adapted from Gilbert et al. (2011). Sample items included "I feel confident" and "I feel like I really appreciate my work" $(\alpha=.88 ; 1=$ almost never to $5=$ almost always $)$.

Withdrawal. At Time 3, we measured participants' self-reported withdrawal with a four-item scale from Spector et al., (2006). Sample items included "Came to work late without permission" and "Stayed home from work and said you were sick when you were not" $(\alpha=.72 ; 1=$ almost never to $5=$ almost always $)$.

Perceived organizational obstruction. At Time 3, perceived organizational obstruction was measured with a five-item scale from Gibney et al. (2009). Sample items included "My organization is a detriment to my well-being" and "The company blocks my personal goals" $(\alpha=.95 ; 1=$ strongly disagree to $5=$ strongly agree $)$.

Control variables. We controlled for age, job tenure, if employees were from public or private organization, and their sector activity. Age and tenure are commonly associated with FSB in the literature (e.g., Vandenberghe et al., 2019) and are related to well-being (Sonnentag, 2015) and withdrawal (Hanisch \& Hulin, 1990). Furthermore, the dynamics of well-being and withdrawal over time are linked to the work environment (Sonnentag, 2015) and thus could be related to the sectors in which the employee evolves.

\section{Results}

Prior to the hypothesized path analysis model, analysis of variance (ANOVA), and Bonferroni and Tukey's post-hoc analyses, were carried out to test if mean differences, regarding scores of feedbacks seeking, individual task adaptivity, well-being involvement, withdrawal, and POO, were attributable to sector variables (private versus public, and activity sector). These preliminary analyses allowed to determine if the sector in which employees evolved created potential disparities preventing generalization of future results. No significant 
results were observed (all $p>.05$ ), confirming that scores related to the sector distribution should not lead to non-random sampling.

To assess the independency of the selected variables, a confirmatory factor analysis (CFA) using maximum likelihood with robust standard errors was conducted using Mplus 8.3 (Muthén \& Muthén, 2017). To determine which was the better model, we used model fit indices scores. Usually, for root mean square error of approximation (RMSEA) and standardized root mean square residual (SRMR) scores, a value less than or equal to .08 indicates an acceptable fit (Browne \& Cudeck, 1992), a value of .06 or less indicates a good fit model (Hu \& Bentler, 1999), and a value less than .05 indicates a very good fit (MacCallum et al., 1996). For comparative fit index (CFI) and Tucker-Lewis index (TLI), the general rule of thumb is to accept a value greater than .90 for an acceptable model (Brown, 2015) and a value greater than .95 for a very good model (Hu \& Bentler, 1999). Finally, the lower the Akaike information criterion (AIC) and Bayesian information criterion (BIC) scores are, the more parsimonious the model tested is. The thresholds selected for this paper are presented in Table 1.

The CFA results showed that the hypothesized five-factor model (0), composed of feedback seeking, individual task adaptivity, well-being involvement, withdrawal, and POO, outperformed, $\chi^{2}(178)=338.95, p<.01 ; \mathrm{RMSEA}=.06 ; \mathrm{CFI}=.93 ; \mathrm{TLI}=.92 ; \mathrm{SRMR}=.05$; AIC $=14,190.97 ; \mathrm{BIC}=14,458.07$, fourteen alternative models $($ Table 1$)$. The initial model (0) surpassed models such as, for the most relevant, a four-factor model (1) that combined feedback seeking and individual task adaptivity, $\chi^{2}(182)=414.71, p<.01 ; \operatorname{RMSEA}=.07$; $\mathrm{CFI}=.90 ; \mathrm{TLI}=.88 ; \mathrm{SRMR}=.07 ; \mathrm{AIC}=14,266.79 ; \mathrm{BIC}=14,519.81 ; \Delta \chi^{2}(4)=86.64, p<$ .01 , a three-factor model (7) that grouped feedback seeking with individual task adaptivity, and well-being involvement with withdrawal feedback, $\chi^{2}(185)=550.49, p<.01$; RMSEA $=$ $.09 ; \mathrm{CFI}=.84 ; \mathrm{TLI}=.82 ; \mathrm{SRMR}=.09 ; \mathrm{AIC}=14,410.17 ; \mathrm{BIC}=14,652.01, \Delta \chi^{2}(3)=93.63, p$ 
$<.01$, a two-factor model (12) that combined feedback seeking, individual task adaptivity with POO, and well-being involvement with withdrawal feedback, $\chi^{2}(187)=820.44, p<.01$; $\mathrm{RMSEA}=.11 ; \mathrm{CFI}=.72 ; \mathrm{TLI}=.69 ; \mathrm{SRMR}=.11 ; \mathrm{AIC}=14,710.32 ; \mathrm{BIC}=14,944.93 ;$ $\Delta \chi^{2}(2)=183.97, p<.01$, and a one-factor (14) model that encompassed all the five variables, $\chi^{2}(202)=1,908.00, p<.01 ; \mathrm{RMSEA}=.18 ; \mathrm{CFI}=.25 ; \mathrm{TLI}=.22 ; \mathrm{SRMR}=.25 ; \mathrm{AIC}=$ $15,942.16 ; \mathrm{BIC}=16,122.63 ; \Delta \chi^{2}(15)=956.78, p<.01$. The hypothesized five-factor model supported the discriminant validity of the used variables.

\section{<Insert Table 1 Here >}

The separation of independent, mediated and dependent variables should reduce the potential for common method variance associated with the use of self-report data. However, well-being involvement, withdrawal and POO were measured at the same time. According to Podsakoff et al. (2003), an orthogonal latent factor encompassing all the variables items and named common method variance (CMV) was added to the initial model (0). Model fit indices scores improved, $\chi^{2}(158)=283.767, p<.01 ; \mathrm{RMSEA}=.05 ; \mathrm{CFI}=.94 ; \mathrm{TLI}=.92 ; \mathrm{SRMR}=$ $.04 ; \mathrm{AIC}=14,147.34 ; \mathrm{BIC}=14,486.63$, but correlation between latent factor remained unchanged. The CMV factor accounted for $26.46 \%$ of the total variance, not slightly more than the average portion of the variance (26\%) usually observed in self-reported studies (Williams et al., 1989). Therefore, the probability of common method bias was low.

Means, standard deviation and observed correlation are reported in Table 2. We tested internal consistency by using Cronbach's alpha and Omega indices (Peters, 2014). Cronbach's alphas are reported in measures description and Omega in Table 2. The internal consistency showed good reliabilities scores $(\alpha \geq .72 ; \Omega \geq .74)$, setting aside the individual task adaptivity ( $\alpha=.67 ; \Omega=.69$ ). Well-being involvement and POO were highly correlated ( $r$ $=-.62, p<.01)$. Correlations between the other variables showed low to moderate scores $(r=$ -.13 to $.28, p<.05)$. Concerning the control variables, negative correlations were observed 
between tenure in job, feedback seeking $(r=-.14, p<.05)$ and individual task adaptivity $(r=$ $-.12, p<.05)$. Moreover, a negative relationship between sector activity and feedback seeking was also obtained $(r=-.15, p<.05)$.

\section{<Insert Table 2 Here $>$}

The hypothesized structural mediation model involving feedback seeking, individual task adaptivity, well-being involvement, and withdrawal, was tested using Shrout and Bolger (2002) recommendations for mediation analyses (see Figure 1). Analyses were conducted by structural equation modelling using MLF estimator. The hypothesized structural model fitted adequately the data, $\chi^{2}(99)=167.654, p<.001 ; \mathrm{RMSEA}=.05 ; \mathrm{CFI}=.94 ; \mathrm{TLI}=.92 ; \mathrm{SRMR}$ $=.05 ; \mathrm{AIC}=10,861.64 ; \mathrm{BIC}=11,052.94$. To determine whether this model was the more suitable, one alternative models, adding direct paths between feedback seeking, well-being involvement, and withdrawal, was tested. The alternative model did not significantly improve over the hypothesized model, $\chi^{2}(97)=176.318, p<.001 ;$ RMSEA $=.05 ;$ CFI $=.94 ;$ TLI $=$ $\left..92 ; \mathrm{SRMR}=.05 ; \mathrm{AIC}=10,862.02 ; \mathrm{BIC}=11,060.54 ; \Delta \chi^{2}(2)=5.48, p=n s\right)$. Hypothesized model structure was retained for structural equation modelling analysis. Based on the Hypothesized model structure, we analyzed the effect of control variables on individual task adaptivity, affective well-being involvement and withdrawal. Among the different control variables, only the organizational tenure showed significant results and was related to wellbeing, $\beta=.15, p<.05 ; \beta=.37, p<.01$. By adding organizational tenure to the model, good fit indices, $\chi^{2}(149)=273.198, p<.001 ; \mathrm{RMSEA}=.05 ; \mathrm{CFI}=.91 ; \mathrm{TLI}=.90 ; \mathrm{SRMR}=.05 ; \mathrm{AIC}$ $=10,865.33 ; \mathrm{BIC}=11,107.17$, and no modification to the hypothesized model were observed. The standardized path coefficients, the standardized indirect effect, and the $95 \%$ confidences (95\% CI) intervals are reported in Table 3.

\section{<Insert Table 3 Here>}


Hypothesis 1 stated that feedback seeking was positively related to individual adaptivity. Hypothesis 1 was supported $(\beta=.32, p<.01)$. Hypothesis 2 predicted the existence of a positive indirect path between feedback seeking and well-being involvement through individual adaptivity. First, a significant positive relation between individual adaptivity and well-being involvement was observed $(\beta=.40, p<.01)$. Second, the indirect effect from feedback seeking to well-being via individual adaptivity was found positive, estimate $=.15,95 \%$ CI $[.03, .27]$, validating Hypothesis 2. Hypothesis 3 predicted the existence of a negative indirect path between feedback seeking and withdrawal through individual adaptivity. First, a significant negative relation between individual adaptivity and withdrawal was observed $(\beta=-.38, p<.01)$. Second, the indirect effect from feedback seeking to withdrawal via individual adaptivity was found negative, estimate $=-.12,95 \% \mathrm{CI}$ [-.23, -.02], validating Hypothesis 3. The Hypothesized mediation model (Model 1) was thus confirmed (Table 3).

Hypotheses 4 and 5 stated that perceived organizational obstruction played a moderating role between individual adaptivity, well-being and withdrawal. To ensure that the moderation effect was not observed because of a mixed product of variance sharing between the outcomes, we first tested the hypothesis in different models ${ }^{2}$. Hypothesis 4 predicted that perceived organizational obstruction should moderate positively the relationship between individual adaptivity and well-being involvement. The "perceived organizational obstruction" $\mathrm{X}$ “well-being involvement” interaction term was statistically significant $(\beta=.32, p<.01)$.

\footnotetext{
${ }^{2}$ Results presented in the main text are obtained using structural equation modelling and latent variables on MPLUS 8.3 by using random type, MLF, and Montecarlo integration (1000). We replied the analysis with a complementary approach using the macro Process to test moderate mediation models with mean scores. Similar results were observed: (a) Interaction term for Hypotheses $4(\beta=.15, p<.01)$ and 5 ( $\beta$ $=-.09, p<.01)$ were significant, (b) individual adaptivity was positively related to well-being $(\beta=.37$, $p<.01)$ and negatively to withdrawal $(\beta=-.26, p<.01)$ when perceived organizational obstruction was high and unrelated when it was low $(\beta=-.00, p=n s ; \beta=-.02, p=n s)$, (c) index of moderated mediation were significant for the path from feedback to well-being (estimate $=.04,95 \%$ CI $[.01, .07]$, and nonsignificant for the path from feedback seeking to withdrawal (estimate $=-.02, p=, 95 \%$ CI [-.05, .00].
} 
The results from the simple slope test showed that in case of High perceived organizational obstruction, individual adaptivity was positively and significantly related to well-being ( $\beta=$ $.33, p<.01)$, whereas in the case of low perceived organizational obstruction, the relationship was no more significant $(\beta=.03, p=\mathrm{ns})$. Moreover, the indirect path from feedback seeking to well-being through individual adaptivity was significant, estimate $=.14, p=.01,95 \% \mathrm{CI}$ $[.02, .27]$. Hypothesis 5 proposed that the perceived organizational obstruction should moderate negatively the relationship between individual adaptivity and withdrawal. The "perceived organizational obstruction" X "withdrawal" interaction term was statistically significant $(\beta=-.22, p<.01)$. The results from the simple slope test showed that in case of High perceived organizational obstruction, individual adaptivity was negatively and significantly related to withdrawal $(\beta=-.26, p<.01)$, whereas in the case of low perceived organizational obstruction, the relationship was no more significant $(\beta=-.06, p=n s)$. Moreover, the indirect path from feedback seeking to withdrawal through individual adaptivity was non-significant, estimate $=-.10, p=.05,95 \% \mathrm{CI}[-.20, .00]$.

Second, we tested Hypotheses 4 and 5 in a common model (Model 2). The results were significantly like our separated previous analysis (Table 3). Indeed, the "perceived organizational obstruction" $\mathrm{X}$ "well-being involvement" $(\beta=.33, p<.01)$ and "perceived organizational obstruction" $\mathrm{X}$ "withdrawal” $(\beta=-.24, p<.05)$ interaction term were statistically significant. To interpret the nature of interaction effect, we conducted a simple slope test and graphically represent the moderating effect of high ( +1 above the mean) and low ( -1 above the mean) level of perceived organizational obstruction, on the relationship between individual adaptivity and the outcomes. As observed in Figure 2, individual adaptivity was more positively related to well-being when perceived organizational obstruction was high $(\beta=.33, p<.01)$ rather than low $(\beta=.04, p<.01)$. As shown in Figure 3 , individual adaptivity was more negatively related to withdrawal when perceived 
organizational obstruction was high $(\beta=-.27, p<.01)$ rather than low $(\beta=-.05, p<.01)$. Therefore, Hypotheses 4 and 5 were supported. Despite the significant interactions observed, the indirect path from feedback seeking to withdrawal through individual adaptivity was nonsignificant, estimate $=.14, p=.02,95 \% \mathrm{CI}[.02, .26]$, contrary to the indirect path from feedback seeking to well-being, estimate $=.10, p=.05,95 \%$ CI $[-.22, .00]$.

\section{<Insert Figure 2 Here> \\ <Insert Figure 3 Here >}

\section{Discussion}

The core contribution of this research was twofold. The first was to show that FSB related indirectly to withdrawal and well-being through individual adaptivity following a selfregulatory process. The second contribution highlighted how adaptive performance would prepare individuals to deal with the negative impact of POO. Results demonstrated thus that FSB increased adaptive performance and they also showed that a positive indirect path between FSB and well-being through adaptive performance existed. Furthermore, our results demonstrated a negative indirect path between FSB and withdrawal through adaptive performance. Finally, we found an interaction effect in which POO increases the relation between adaptive performance and well-being and decreases the relation between adaptive performance and withdrawal.

Our results advanced the literature of the FSB and adaptive performance in multiple ways. First, our model extended the understanding of the complementary view of FSB and adaptivity by demonstrating that FSB participates in the adaptation of employees in the workplace. The strength of this finding allowed understanding why proactive people using FSB could have a better adjustment in the organizational socialization process (Bauer et al., 2007). The proactive actions would enable employees to have an active adjustment (e.g., role clarification, building relationships with organizational members, coping with adverse 
situations). This research contributed to confirm results from Chan and Schmitt (2000) who demonstrated that proactivity was related to adaptation in the workplace. Second, our study investigated broader and distal outcomes of the adaptive process (Jundt et al., 2015). The results suggest that adaptivity in the workplace boosted employee well-being and reduced the intent to lessen participation in the organization (e.g., lateness, absenteeism). Our findings advocated that employees who were well adapted to the organization had a higher well-being to it and more involved in its goals (Bauer et al., 2007). Thus, employees would be less likely to adopt behaviors that hinder the achievement of the organizational objectives as lateness or absenteeism (Hanisch \& Hulin, 1990). These findings expanded our knowledge of the largely neglected well-being perspective (Gruman \& Sacks, 2013). The literature concentrated on trying to understand how to increase adaptive performance (Pulakos et al., 2000) but largely ignored the outcomes of adaptive performance (Jundt et al., 2015). Therefore, as we have assumed, when an individual adapts to his or her team or organization because of FSB through a self-regulated approach, he or she enhances organizational involvement. Third, we examined the positive effects of adaptive performance on adverse situations. Our study sheds light that well-adapted employees could cope with POO. This process was explained by the fact that employees who were adapted could turn to other resources like relational resources rather than organizational resources. In addition, the results showed that the more senior the individual's job tenure, the more well-being was enhanced by prior use of FSB in a context of perceived organizational obstruction. However, the observed effect from POO on the relationship between adaptivity and withdrawal indicated that even if adapted people succeed to deal with POO, they tend to withdraw to protect themselves. These results are partially consistent with those observed by Akhtar et al. (2020). Indeed, their model showed that the more individuals were ostracized, the more they tended to develop a facade of conformity that led them to generate unethical behaviors at work harming the organizational interest, 
especially in a POO context. Fostering adaptation processes through FSB should thus reduce the emergence of unethical behavior at work. However, our results obtained in relation to withdrawal behaviors seem to indicate that individuals would tend to disengage from their organization. Since withdrawal processes are one of the first phases in the emergence of destructive deviant behavior (Spector et al., 2006), it is conceivable that the positive consequences obtained on well-being cannot be sustained in a POO context. Moreover, the results related to adaptivity in the POO context suggest that employees would favor a passive rather than active action. Therefore, there is a need to study the long-term impact of POO on the emergence of proactive behaviors such as FSB. According to self-regulation theories, future research should investigate the individual, team, and organizational (e.g., learning goal orientation, self-leadership strategies, team climate for voice) construct that would reduce the negative effects of POO. Future research should also investigate the factors that could impact the relation between adaptivity and withdrawal. It would also be useful to analyze the role of organizational support in the moderating effect of the POO. Lastly, one contribution of this study is the time lagged nature of the data collection. Data were collected at three different periods and allows a stronger strength of the conclusion study (Ployhart \& Vandenberg, 2010).

This study has also practical implications. First, developing FSB behaviors in organizations could be positive not only to foster organizational effectiveness (e.g., increase of organizational commitment, decrease of turnover intentions) but also it could be a valuable behavior to be promoted to facilitate the workforce adaptivity to a more changing and interdependent organizational system (Griffin et al., 2007). Consistent with other research, our findings highlight the importance of supporting FSB in organizations to promote organizational competitiveness (e.g., diminishing withdrawal behaviors) (e.g., Vandenberghe et al., 2019; Whitaker et al., 2007). Indeed, FSB is framed within the impression management 
and performance enhancement literature (Ashford et al., 2016; Tsui et al., 1995). The impression management framework asserts that people may use FSB as a means of generating good impressions in the workplace (Moss et al., 2003). Thus, FSB may be mainly motivated by the desire to protect or enhance one's public image in organizations (Moss et al., 2003). In that regard, there are several ways to promote FSB in organizations. For instance, managers can try to reward employees who seek feedback (Ashford et al., 2003). By doing so, they will participate to create work conditions where the employees can speak freely without worrying about the negative consequences of this act. Consequently, fostering FSB represents a challenge for managers and practitioners.

Second, even though FSB can promote adaptivity, which in turn can improve wellbeing and reduce withdrawal behaviors at work, minimizing the impact of a perceived organizational obstruction is also an important issue for organizations. In general, perceptions of organizational obstruction not only might create a representation that the organization is detrimental for employees but also could create organizational misbehavior (Gibney et al., 2011). Our findings suggest that indeed such negative perception can negatively affect the proactive and adaptive employees' behavior. Therefore, from a practical standpoint, it would be useful to identify and tackle the organizational factors that can create the negative perception concerning the organizational environment. As an example, managers can point out the negative conditions (e.g., abusive leadership) and ensuring that these conditions will be no more present in the organization, and then informing the employees about these new conditions in order to create a perception of organizational support (Chreim, 2002). Hence, being attentive to employees' perceptions concerning a possible organizational obstruction is important to create an enabling environment for proactive and adaptive behaviors.

Although these findings are promising, this study has some limitations. We collected the answers at multiple times which limits the common method variance, but the 
heterogeneity of our data and the random nature of the sample can inflate the common method variance (Podsakoff et al., 2003). This leads to the second limitation: the nature of the sample. Given the random nature of the sample, we could not examine the role of control variables like context-specific variables or the nature of jobs. The occupational context influences the design of jobs, for example in certain occupations, it is easier to obtain feedback, have more social support and requires more personal initiative (Humphrey et al., 2007). For instance, the occupational context and design of jobs could moderate some variables of this study like feedback seeking or others. Notably, the work characteristics significantly influence the satisfaction and well-being at work (Humphrey et al., 2007). A third limitation of this study is the dropout of participants at different times of measure. More than $50 \%$ of participants does not respond between Time 1 and Time 3 . This important loss of participants can limit the generalizability of our findings. A fourth limitation of this study is related to the use of the desire for involvement variable rather than the full Gilbert et al.'s (2011) well-being scale. The objective was to study the consequences of the relationship between FSB and adaptivity in a POO context on psychological attachment variables such as well-being and withdrawal. In this sense, our research studies only the effect on the desire for involvement and not total well-being at work. Future research will focus on analyzing the effect of our model on all dimensions of well-being. A final limitation relates to the use of adaptive performance to analyze the relationship between FSB and adaptivity. Indeed, adaptive performance measurement is part of a model integrating proactivity, adaptivity and proficiency (Griffin et al., 2007). However, the use of FSB rather than other proactive behavior (i.e., taking charge, voice, personal initiative, proactive performance) reduces potential bias. Indeed, it has been shown that the previous measures of proactivity were inconsistent with the definition of the construct they assess (Cho et al., 2020). According to the results obtained by Parker and Collins (2010), the risk of contamination between 
constructs should not concern FSB, as it was not part of the second-order factor of proactive work behavior, but of proactive person-environment fit behavior. FSB therefore measures a different perspective of proactivity from that implied in proactive performance. Moreover, the correlations scores between the two second-order factors were moderate (Parker \& Collins, 2010), thus reducing possible contamination bias between the proactive dimension of FSB and adaptive performance.

This study provides a clarification of the links between proactivity and adaptivity. In the future, one challenge for researchers will be to enhance our understanding of how different types of proactive work behaviors are related to adaptivity. It is possible that proactive person-environment fit behaviors (Parker \& Collins, 2010) may lead to individual adaptivity because they aim at creating compatibility between the individual and the environment. Examples of these behaviors are feedback monitoring, job negotiation and career initiative. Second, it is also possible that adaptivity and proactivity increase each other in a self-reinforcing cycle. Indeed, Strauss et al. (2015) found that adaptivity creates optimal conditions for the adoption of proactive behaviors. Therefore, the relationship between the two constructs might not be unilateral. In addition, a learning orientation has been shown to positively predict the proactive and adaptive performance of work roles (Marques-Quinteiro \& Curral, 2012). Therefore, future research using a self-regulated perspective should investigate, through longitudinal analysis, the role played by learning orientation in the potential co-evolutionary relationship between adaptability and proactivity, in order to better understand how one may impact the other. Third, future research could further expand our knowledge with the study of within-person level. Our research is the first step by the use of time lagged design but the adoption of methods as Latent Growth Model or Latent Change Score can foster our understanding of the effect of time and within-person variability. 
To conclude, our study aimed at exploring to which extent adaptivity represents a mechanism through which feed-back seeking affects psychological attachment. Furthermore, the role played by the interaction POO between adaptivity and psychological attachment was analyzed. Findings of the present study revealed that adaptivity positively mediated the relation between FSB and desire for involvement, and negatively mediated the relation between FSB and withdrawal. Results also showed that adaptivity played a major role in POO context. It helped employees to deal with the perception of obstruction by enhancing their well/being. However, POO reduced the effect of adaptivity on withdrawal, increasing thus over time the risks of employee's withdrawal. Through the findings of our study, we can propose to managers and organizations confronted with POO to foster research and practices oriented towards organizational learning by promoting the dual emergence of proactive behaviors and adaptive performance. 


\section{References}

Anseel, F., Beatty, A. S., Shen, W., Lievens, F., \& Sackett, P. R. (2015). How are we doing after 30 years? A meta-analytic review of the antecedents and outcomes of feedback-seeking behavior. Journal of Management, 41(1), 318-348. https://doi.org/10.1177/0149206313484521

Akhtar, M. W., Syed, F., Javed, M., \& Husnain, M. (2020). Grey shade of work environment triadeffect of supervisor ostracism and perceived organizational obstruction on employees' behaviour: A moderated-mediation model. Leadership \& Organization Development Journal, 41(5), 669-686. https://doi.org/10.1108/LODJ-07-2019-0334

Ashford, S. J. (1986). Feedback-seeking in individual adaptation: A resource perspective. Academy of Management Journal, 29(3), 465-487. https://doi.org/10.5465/256219

Ashford, S. J., \& Black, J. S. (1996). Proactivity during organizational entry: The role of desire for control. Journal of Applied Psychology, 81(2), 199-214. https://doi.org/10.1037/0021$\underline{9010.81 .2 .199}$

Ashford, S. J., Blatt, R., \& VandeWalle, D. (2003). Reflections on the looking glass: A review of research on feedback-seeking behavior in organizations. Journal of Management, 29(6), 773799. https://doi.org/10.1016/S0149-2063(03)00079-5

Ashford, S. J., \& Cummings, L. L. (1983). Feedback as an individual resource: Personal strategies of creating information. Organizational Behavior and Human Performance, 32(3), 370-398. https://doi.org/10.1016/0030-5073(83)90156-3

Ashford, S. J., De Stobbeleir, K., \& Nujella, M. (2016). To seek or not to seek: Is that the only question? Recent developments in feedback-seeking literature. Annual Review of Organizational Psychology and Organizational Behavior, 3, 213-239. https://doi.org/10.1146/annurev-orgpsych-041015-062314

Ashforth, B. E., Harrison, S. H., \& Corley, K. G. (2008). Identification in organizations: An examination of four fundamental questions. Journal of Management, 34(3), 325-374. https://doi.org/10.1177/0149206308316059 
Ashford, S. J., \& Tsui, A. S. (1991). Self-regulation for managerial effectiveness: The role of active feedback seeking. Academy of Management Journal, 34(2), 251-280. https://doi.org/10.5465/256442

Baard, S. K., Rench, T. A., \& Kozlowski, S. W. J. (2014). Performance adaptation: A theoretical integration and review. Journal of Management, 40(1), 48-99. https://doi.org/10.1177/0149206313488210

Bandura, A. (2001). Social cognitive theory: An agentic perspective. Annual Review of Psychology, 52(1), 1-26. https://doi.org/10.1146/annurev.psych.52.1.1

Bauer, T. N., Bodner, T., Erdogan, B., Truxillo, D. M., \& Tucker, J. S. (2007). Newcomer adjustment during organizational socialization: A meta-analytic review of antecedents, outcomes, and methods. Journal of Applied Psychology, 92(3), 707-721. https://doi.org/10.1037/0021$\underline{9010.92 .3 .707}$

Berg, J. M., Wrzesniewski, A., \& Dutton, J. E. (2010). Perceiving and responding to challenges in job crafting at different ranks: When proactivity requires adaptivity. Journal of Organizational Behavior, 31(2-3), 158-186. https://doi.org/10.1002/job.645

Bindl, U. K., \& Parker, S. K. (2010). Feeling good and performing well? Psychological engagement and positive behaviors at work. In S. L. Albrecht (Ed.), Handbook of employee engagement: Perspectives, issues, research and practice (pp. 385-398). Edward-Elgar Publishing. http://doi.org/10.4337/9781849806374.00043

Blau, G. J. (1985). Relationship of extrinsic, intrinsic, and demographic predictors to various types of withdrawal behaviors. Journal of Applied Psychology, 70(3), 442-450. https://doi.org/10.1037/0021-9010.70.3.442

Brislin, R. W. (1970). Back-translation for cross-cultural research. Journal of Cross-Cultural Psychology, 1(3), 185-216. https://doi.org/10.1177/135910457000100301

Brown, T. A. (2015). Confirmatory factor analysis for applied research. Guilford.

Browne, M. W., \& Cudeck, R. (1992). Alternative ways of assessing model fit. Sociological Methods \& Research, 21(2), 230-258. https://doi.org/10.1177/0049124192021002005 
Cangialosi, N., Odoardi, C., \& Battistelli, A. (2020). Learning climate and innovative work behavior, the mediating role of the learning potential of the workplace. Vocations and Learning, 13(2), 263-280. https://doi.org/10.1007/s12186-019-09235-y

Carpini, J. A., Parker, S. K., \& Griffin, M. A. (2017). A look back and a leap forward: A review and synthesis of the individual work performance literature. Academy of Management Annals, 11(2), 825-885. https://doi.org/10.5465/annals.2015.0151

Chan, D., \& Schmitt, N. (2000). Interindividual differences in intraindividual changes in proactivity during organizational entry: A latent growth modeling approach to understanding newcomer adaptation. Journal of Applied Psychology, 85(2), 190-210. https://doi.org/10.1037/0021$\underline{9010.85 .2 .190}$

Chiaburu, D. S., \& Harrison, D. A. (2008). Do peers make the place? Conceptual synthesis and metaanalysis of coworker effects on perceptions, attitudes, OCBs, and performance. Journal of Applied Psychology, 93(5), 1082-1103. https://doi.org/10.1037/0021-9010.93.5.1082

Cho, S. S., Carpenter, N. C., \& Zhang, B. (2020). An item-level investigation of conceptual and empirical distinctiveness of proactivity constructs. International Journal of Selection and Assessment 28(3), 337-350. https://doi.org/10.1111/ijsa.12287

Chreim, S. (2002). Influencing organizational identification during major change: A communicationbased perspective. Human Relations, 55(9), 1117-1137. https://doi.org/10.1177/0018726702055009022

Cohen, S., \& Wills, T. A. (1985). Stress, social support, and the buffering hypothesis. Psychological Bulletin, 98(2), 310-357. https://doi.org/10.1037/0033-2909.98.2.310

Cooper-Thomas, H. D., Paterson, N. L., Stadler, M. J., \& Saks, A. M. (2014). The relative importance of proactive behaviors and outcomes for predicting newcomer learning, well-being, and work engagement. Journal of Vocational Behavior, 84(3), 318-331. https://doi.org/10.1016/j.jvb.2014.02.007

Crant, J. M. (2000). Proactive behavior in organizations. Journal of Management, 26(3), 435-462. https://doi.org/10.1177/014920630002600304 
Crommelinck, M., \& Anseel, F. (2013). Understanding and encouraging feedback-seeking behavior: A literature review. Medical Education, 47(3), 232-241. https://doi.org/10.1111/medu.12075 Cullen, K. L., Edwards, B. D., Casper, W. C., \& Gue, K. R. (2014). Employees' adaptability and perceptions of change-related uncertainty: Implications for perceived organizational support, job satisfaction, and performance. Journal of Business and Psychology, 29(2), 269-280. https://doi.org/10.1007/s10869-013-9312-y

Dagenais-Desmarais, V., \& Savoie, A. (2012). What is psychological well-being, really? A grassroots approach from the organizational sciences. Journal of Happiness Studies, 13(4), 659-684. https://doi.org/10.1007/s10902-011-9285-3

De Stobbeleir, K., Ashford, S., \& Zhang, C. (2020). Shifting focus: Antecedents and outcomes of proactive feedback seeking from peers. Human Relations, 73, 303-325. https://doi.org/10.1177/0018726719828448

Edwards, J. R. (2008). 4. Person-environment fit in organizations: An assessment of theoretical progress. Academy of Management Annals, 2(1), 167-230. https://doi.org/10.5465/19416520802211503

Eisenberger, R., \& Stinglhamber, F. (2011). Perceived organizational support: Fostering enthusiastic and productive employees. American Psychological Association. https://doi.org/10.1037/12318-000

Ellis, A. M., Bauer, T. N., Mansfield, L. R., Erdogan, B., Truxillo, D. M., \& Simon, L. S. (2015). Navigating uncharted waters: Newcomer socialization through the lens of stress theory. Journal of Management, 41(1), 203-235. https://doi.org/10.1177/0149206314557525

Frese, M., \& Fay, D. (2001). 4. Personal initiative: An active performance concept for work in the 21st century. Research in Organizational Behavior, 23, 133-187. https://doi.org/10.1016/S0191-3085(01)23005-6

Ghitulescu, B. E. (2013). Making change happen: The impact of work context on adaptive and proactive behaviors. The Journal of Applied Behavioral Science, 49(2), 206-245. https://doi.org/10.1177/0021886312469254 
Gibney, R., Zagenczyk, T. J., Fuller, J. B., Hester, K., \& Caner, T. (2011). Exploring organizational obstruction and the expanded model of organizational identification. Journal of Applied Social Psychology, 41(5), 1083-1109. https://doi.org/10.1111/j.1559-1816.2011.00748.x

Gibney, R., Zagenczyk, T. J., \& Masters, M. F. (2009). The negative aspects of social exchange: An introduction to perceived organizational obstruction. Group \& Organization Management, 34(6), 665-697. https://doi.org/10.1177/1059601109350987

Gilbert, M. H., Dagenais-Desmarais, V., \& Savoie, A. (2011). Validation d'une mesure de santé psychologique au travail [Validation of a psychological health measure]. European Review of Applied Psychology, 61(4), 195-203. https://doi.org/10.1016/j.erap.2011.09.001

Gong, Y., Wang, M., Huang, J.-C., \& Cheung, S. Y. (2017). Toward a goal orientation-based feedback-seeking typology: Implications for employee performance outcomes. Journal of Management, 43(4), 1234-1260. https://doi.org/10.1177/0149206314551797

Grant, A. M., \& Ashford, S. J. (2008). The dynamics of proactivity at work. Research in Organizational Behavior, 28, 3-34. https://doi.org/10.1016/j.riob.2008.04.002

Griffeth, R. W., Gaertner, S., \& Sager, J. K. (1999). Taxonomic model of withdrawal behaviors: The adaptive response model. Human Resource Management Review, 9(4), 577-590. https://doi.org/10.1016/S1053-4822(99)00034-0

Griffin, M. A., Neal, A., \& Parker, S. K. (2007). A new model of work role performance: Positive behavior in uncertain and interdependent contexts. Academy of Management Journal, 50(2), 327-347. https://doi.org/10.5465/AMJ.2007.24634438

Griffin, M. A., Parker, S. K., \& Mason, C. M. (2010). Leader vision and the development of adaptive and proactive performance: A longitudinal study. Journal of Applied Psychology, 95(1), 174 182. https://doi.org/10.1037/a0017263

Gruman, J. A., \& Saks, A. M. (2013). Organizational socialization and newcomers' psychological capital and well-being. In A. B. Bakker (Ed.), Advances in positive organizational psychology (Vol. 1, pp. 211-236). Emerald Group Publishing Limited. https://doi.org/10.1108/S2046$\underline{410 X(2013) 0000001012}$ 
Han, T. Y., \& Williams, K. J. (2008). Multilevel investigation of adaptive performance: Individualand team-level relationships. Group \& Organization Management, 33(6), 657-684. https://doi.org/10.1177/1059601108326799

Hancock, J. I., Allen, D. G., Bosco, F. A., McDaniel, K. R., \& Pierce, C. A. (2013). Meta-analytic review of employee turnover as a predictor of firm performance. Journal of Management, 39(3), 573-603. https://doi.org/10.1177/0149206311424943

Hanisch, K. A., \& Hulin, C. L. (1990). Job attitudes and organizational withdrawal: An examination of retirement and other voluntary withdrawal behaviors. Journal of Vocational Behavior, 37(1), 60-78. https://doi.org/10.1016/0001-8791(90)90007-O

Harvey, P., Stoner, J., Hochwarter, W., \& Kacmar, C. (2007). Coping with abusive supervision: The neutralizing effects of ingratiation and positive affect on negative employee outcomes. The Leadership Quarterly, 18(3), 264-280. https://doi.org/10.1016/j.leaqua.2007.03.008

Hobfoll, S. E. (1989). Conservation of resources: a new attempt at conceptualizing stress. American Psychologist, 44(3), 513-524. https://doi.org/10.1037/0003-066X.44.3.513

Hu, L., \& Bentler, P. M. (1999). Cutoff criteria for fit indexes in covariance structure analysis: Conventional criteria versus new alternatives. Structural Equation Modeling, 6, 1-55. http://doi.org/10.1080/10705519909540118

Humphrey, S. E., Nahrgang, J. D., \& Morgeson, F. P. (2007). Integrating motivational, social, and contextual work design features: A meta-analytic summary and theoretical extension of the work design literature. Journal of Applied Psychology, 92(5), 1332-1356. https://doi.org/10.1037/0021-9010.92.5.1332

Ibarra, H., \& Barbulescu, R. (2010). Identity as narrative: Prevalence, effectiveness, and consequences of narrative identity work in macro work role transitions. Academy of Management Review, 35(1), 135-154. https://doi.org/10.5465/amr.35.1.zok135

Jundt, D. K., Shoss, M. K., \& Huang, J. L. (2015). Individual adaptive performance in organizations: A review. Journal of Organizational Behavior, 36(S1), S53-S71. https://doi.org/10.1002/job.1955 
Kammeyer-Mueller, J. D., \& Wanberg, C. R. (2003). Unwrapping the organizational entry process: Disentangling multiple antecedents and their pathways to adjustment. Journal of Applied Psychology, 88(5), 779-794. https://doi.org/10.1037/0021-9010.88.5.779

Kozlowski, S. W. J., Gully, S. M., Brown, K. G., Salas, E., Smith, E. M., \& Nason, E. R. (2001). Effects of training goals and goal orientation traits on multidimensional training outcomes and performance adaptability. Organizational Behavior and Human Decision Processes, 85(1), 131. https://doi.org/10.1006/obhd.2000.2930

Krasman, J. (2011). Taking feedback-seeking to the next "level": Organizational structure and feedback-seeking behavior. Journal of Managerial Issues, 23(1), 9-30.

Lam, L. W., Peng, K. Z., Wong, C.-S., \& Lau, D. C. (2017). Is more feedback seeking always better? Leader-member exchange moderates the relationship between feedback-seeking behavior and performance. Journal of Management, 43(7), 2195-2217. https://doi.org/10.1177/0149206315581661

Locke, E. A., \& Latham, G. P. (2006). New directions in goal-setting theory. Current Directions in Psychological Science, 15(5), 265-268. https://doi.org/10.1111/j.1467-8721.2006.00449.x

MacCallum, R. C., Browne, M. W., \& Sugawara, H. M. (1996). Power analysis and determination of sample size for covariance structural modeling. Psychological Methods, 1, 130-149. http://doi.org/10.1037/1082-989X.1.2.130

Marchand, C., \& Vandenberghe, C. (2016). Perceived organizational support, emotional exhaustion, and turnover: The moderating role of negative affectivity. International Journal of Stress Management, 23(4), 350-375. https://doi.org/10.1037/str0000020

Marques-Quinteiro, P., \& Curral, L. A. (2012). Goal orientation and work role performance: Predicting adaptive and proactive work role performance through self-leadership strategies. The Journal of Psychology: Interdisciplinary and Applied, 146(6), 559-577. https://doi.org/10.1080/00223980.2012.656157

Morrison, E. W. (1993). Longitudinal study of the effects of information seeking on newcomer socialization. Journal of Applied Psychology, 78(2), 173-183. https://doi.org/10.1037/0021$\underline{9010.78 .2 .173}$ 
Morrison, E. W. (2002). Newcomers' relationships: The role of social network ties during socialization. Academy of Management Journal, 45(6), 1149-1160. https://doi.org/10.5465/3069430

Moss, S. E., Valenzi, E. R., \& Taggart, W. (2003). Are you hiding from your boss? The development of a taxonomy and instrument to assess the feedback management behaviors of good and bad performers. Journal of Management, 29(4), 487-510. https://doi.org/10.1016/S0149$\underline{2063 \quad 03 \quad 00022-9}$

Muthén, L. K., \& Muthén, B. (2017). Mplus user's guide: Statistical analysis with latent variables, user's guide. Muthén \& Muthén.

Park, S., \& Park, S. (2019). Employee adaptive performance and its antecedents: Review and synthesis. Human Resource Development Review, 18(3), 294-324. https://doi.org/10.1177/1534484319836315

Parker, S. K., \& Collins, C. G. (2010). Taking stock: Integrating and differentiating multiple proactive behaviors. Journal of Management, 36(3), 633-662. https://doi.org/10.1177/0149206308321554

Peters, G. J. Y. (2014). The alpha and the omega of scale reliability and validity: Why and how to abandon Cronbach's alpha. European Health Psychologist, 16(2), 56-69.

Ployhart, R. E., \& Vandenberg, R. J. (2010). Longitudinal research: The theory, design, and analysis of change. Journal of Management, 36(1), 94-120. https://doi.org/10.1177/0149206309352110

Podsakoff, N. P., LePine, J. A., \& LePine, M. A. (2007). Differential challenge stressor-hindrance stressor relationships with job attitudes, turnover intentions, turnover, and withdrawal behavior: A meta-analysis. Journal of Applied Psychology, 92(2), 438-454. https://doi.org/10.1037/0021-9010.92.2.438

Podsakoff, P. M., MacKenzie, S. B., \& Podsakoff, N. P. (2012). Sources of method bias in social science research and recommendations on how to control it. Annual Review of Psychology, 63, 539-569. https://doi.org/10.1146/annurev-psych-120710-100452 
Podsakoff, P. M., MacKenzie, S. B., Lee, J.-Y., \& Podsakoff, N. P. (2003). Common method biases in behavioral research: A critical review of the literature and recommended remedies. Journal of Applied Psychology, 88(5), 879-903. https://doi.org/10.1037/0021-9010.88.5.879

Pulakos, E. D., Arad, S., Donovan, M. A., \& Plamondon, K. E. (2000). Adaptability in the workplace: Development of a taxonomy of adaptive performance. Journal of Applied Psychology, 85(4), 612-624. https://doi.org/10.1037/0021-9010.85.4.612

Roznowski, M., \& Hanisch, K. A. (1990). Building systematic heterogeneity into work attitudes and behavior measures. Journal of Vocational Behavior, 36(3), 361-375. https://doi.org/10.1016/0001-8791(90)90037-3

Ryan, R. M., \& Deci, E. L. (2001). On happiness and human potentials: A review of research on hedonic and eudaimonic well-being. Annual Review of Psychology, 52(1), 141-166. https://doi.org/10.1146/annurev.psych.52.1.141

Shrout, P. E., \& Bolger, N. (2002). Mediation in experimental and nonexperimental studies: New procedures and recommendations. Psychological Methods, 7(4), 422-445. https://doi.org/10.1037/1082-989X.7.4.422

Somers, M. J. (2009). The combined influence of affective, continuance and normative commitment on employee withdrawal. Journal of Vocational Behavior, 74(1), 75-81. https://doi.org/10.1016/j.jvb.2008.10.006

Sonnentag, S. (2015). Dynamics of well-being. Annual Review of Organizational Psychology and Organizational Behavior, 2(1), 261-293. https://doi.org/10.1146/annurev-orgpsych-032414$\underline{111347}$

Spector, P. E., \& Fox, S. (2002). An emotion-centered model of voluntary work behavior: Some parallels between counterproductive work behavior and organizational citizenship behavior. Human Resource Management Review, 12(2), 269-292. https://doi.org/10.1016/S10534822(02)00049-9

Spector, P. E., Fox, S., Penney, L. M., Bruursema, K., Goh, A., \& Kessler, S. (2006). The dimensionality of counterproductivity: Are all counterproductive behaviors created equal? Journal of Vocational Behavior, 68(3), 446-460. https://doi.org/10.1016/j.jvb.2005.10.005 
Strauss, K., Griffin, M. A., Parker, S. K., \& Mason, C. M. (2015). Building and sustaining proactive behaviors: The role of adaptivity and job satisfaction. Journal of Business and Psychology, 30(1), 63-72. https://doi.org/10.1007/s10869-013-9334-5

Tornau, K., \& Frese, M. (2013). Construct clean-up in proactivity research: A meta-analysis on the nomological net of work-related proactivity concepts and their incremental validities. Applied Psychology, 62(1), 44-96. https://doi.org/10.1111/j.1464-0597.2012.00514.x

Tsui, A. S., Ashford, S. J., Clair, L. S., \& Xin, K. R. (1995). Dealing with discrepant expectations: Response strategies and managerial effectiveness. Academy of Management Journal, 38(6), 1515-1543. https://doi.org/10.5465/256842

Vandenberghe, C., Landry, G., Bentein, K., Anseel, F., Mignonac, K., \& Roussel, P. (2019). A dynamic model of the effects of feedback-seeking behavior and organizational commitment on newcomer turnover. Journal of Management. https://doi.org/10.1177/0149206319850621

VandeWalle, D., \& Cummings, L. L. (1997). A test of the influence of goal orientation on the feedback-seeking process. Journal of Applied Psychology, 82(3), 390-400.

https://doi.org/10.1037/0021-9010.82.3.390

Vohs, K. D., \& Baumeister, R. F. 2004. Understanding self-regulation. In R. F. Baumeister \& K. D. Vohs (Eds.), Handbook of self-regulation (pp.1-9). Guilford.

Walsh, J. P., Ashford, S. J., \& Hill, T. E. (1985). Feedback obstruction: The influence of the information environment on employee turnover intentions. Human Relations, 38(1), 23-46. https://doi.org/10.1177/001872678503800102

Whitaker, B. G., Dahling, J. J., \& Levy, P. (2007). The development of a feedback environment and role clarity model of job performance. Journal of Management, 33(4), 570-591. https://doi.org/10.1177/0149206306297581

Williams, L. J., Cote, J. A., \& Buckley, M. R. (1989). Lack of method variance in self-reported affect and perceptions at work: Reality or artifact? Journal of Applied Psychology, 74(3), 462-468. https://doi.org/10.1037/0021-9010.74.3.462 
Zimmerman, R. D., Swider, B. W., Woo, S. E., \& Allen, D. G. (2016). Who withdraws?

Psychological individual differences and employee withdrawal behaviors. Journal of Applied Psychology, 101(4), 498-519. https://doi.org/10.1037/ap10000068

Zhu, J., Frese, M., \& Li, W. D. (2014). Proactivity and adaptability. In D. Chan (Ed.), Individual adaptability to changes at work: New directions in research (pp. 36-51). Routledge. 
Table 1.

Fit Indices for Confirmatory Factor Analysis

\begin{tabular}{|c|c|c|c|c|c|c|c|c|c|c|c|c|c|}
\hline \multirow{2}{*}{ Model } & \multirow[t]{2}{*}{$\chi^{2}$} & \multirow[t]{2}{*}{$d f$} & \multirow[t]{2}{*}{$\begin{array}{l}\text { RMSEA } \\
\mathrm{a}(\leq .08) \\
\end{array}$} & \multicolumn{2}{|c|}{$\begin{array}{c}\text { RMSEA } \\
90 \% \text { CI }\end{array}$} & \multirow[t]{2}{*}{$\begin{array}{c}\text { CFI } \\
(\geq .9)^{\mathrm{a}} \\
\end{array}$} & \multirow[t]{2}{*}{$\begin{array}{c}\text { TLI } \\
(\geq .9)^{\mathrm{a}} \\
\end{array}$} & \multirow[t]{2}{*}{$\begin{array}{l}\text { SRMR } \\
(\leq .08)^{\mathrm{a}} \\
\end{array}$} & \multirow[t]{2}{*}{ AIC } & \multirow[t]{2}{*}{$\mathrm{BIC}$} & \multirow[t]{2}{*}{$\Delta \mathrm{CFI}$} & \multirow[t]{2}{*}{$\Delta \mathrm{TLI}$} & \multirow[t]{2}{*}{$\Delta \chi^{2}$} \\
\hline & & & & & & & & & & & & & \\
\hline (0) Baseline model & 338.95 & 178 & .06 & .05 & .07 & .93 & .92 & .05 & $14,190.97$ & $14,458.07$ & - & - & - \\
\hline Four factor model & & & & & & & & & & & vs. Mode & $l 0$ & \\
\hline (1) Combining FS and ATI & 414.71 & 182 & .07 & .06 & .08 & .90 & .88 & .07 & $14,266.79$ & $14,519.46$ & -0.03 & -0.04 & $\chi^{2}(4)=86.64 * *$ \\
\hline (2) Combining FS and POO & 607.56 & 182 & .09 & .08 & .10 & .81 & .78 & .09 & $14,479.14$ & $14,731.81$ & -0.12 & -0.13 & $\chi^{2}(4)=217.87 * *$ \\
\hline (3) Combining ATI and POO & 443.10 & 182 & .07 & .06 & .08 & .89 & .87 & .07 & $14,297.77$ & $14,550.44$ & -0.04 & -0.05 & $\chi^{2}(4)=109.71 * *$ \\
\hline (4) Combining WB and WD & 485.60 & 182 & .08 & .07 & .09 & .87 & .85 & .07 & $14,342.55$ & $14,595.22$ & -0.06 & -0.07 & $\chi^{2}(4)=160.82 * *$ \\
\hline (5) Combining WB and POO & 489.15 & 182 & .08 & .07 & .09 & .86 & .84 & .07 & $14,349.66$ & $14,602.32$ & -0.07 & -0.08 & $\chi^{2}(4)=132.59 * *$ \\
\hline (6) Combining WD and POO & 479.99 & 182 & .08 & .07 & .09 & .87 & .85 & .07 & $14,337.86$ & $14,590.52$ & -0.06 & -0.07 & $\chi^{2}(4)=140.76^{* *}$ \\
\hline Three factor model & & & & & & & & & & & vs. Mode & 6 & \\
\hline (7) Combining FS with ATI, and WB with WD & 550.49 & 185 & .09 & .08 & .09 & .84 & .82 & .09 & $14,410.17$ & $14,652.01$ & -0.03 & -0.03 & $\chi^{2}(3)=93.63 * *$ \\
\hline (8) Combining FS with POO, and WB with WD & 749.38 & 185 & .11 & .10 & .11 & .75 & .72 & .11 & $14,630.48$ & $14,872.32$ & -0.12 & -0.13 & $\chi^{2}(3)=218.14^{* *}$ \\
\hline (9) Combining ATI with POO, and WB with WD & 579.81 & 185 & .09 & .08 & .10 & .83 & .80 & .09 & $14,441.87$ & $14,683.70$ & -0.04 & -0.05 & $\chi^{2}(3)=121.47 * *$ \\
\hline (10) Combining ATI with FS, and WB with POO & 551.56 & 185 & .09 & .08 & .09 & .84 & .82 & .08 & $14,414.83$ & $14,656.66$ & -0.03 & -0.03 & $\chi^{2}(3)=74.52 * *$ \\
\hline (11) Combining ATI with FS, and WD with POO & 542.23 & 185 & .08 & .08 & .09 & .84 & .82 & .08 & $14,402.64$ & $14,644.47$ & -0.03 & -0.03 & $\chi^{2}(3)=77.55 * *$ \\
\hline Two factor model & & & & & & & & & & & vs. Mode & 11 & \\
\hline (12) Combining FS, ATI with POO, and WD with WB & 820.44 & 187 & .11 & .10 & .12 & .72 & .69 & .11 & $14,710.32$ & $14,944.93$ & -0.12 & -0.14 & $\chi^{2}(2)=183.97 * *$ \\
\hline (13) Combining FS with ATI, and WD, WB with POO & 678.03 & 187 & .10 & .09 & .11 & .78 & .76 & .10 & $14,552.95$ & $14,787.57$ & -0.06 & -0.06 & $\chi^{2}(2)=106.83^{* *}$ \\
\hline One factor model & & & & & & & & & & & vs. Mod & 14 & \\
\hline (14) Combining FS, ATI, WD, WB and POO & $1,908.00$ & 202 & .18 & .17 & .18 & .25 & .22 & .25 & $15,942.16$ & $16,122.63$ & -0.54 & -0.54 & $\chi^{2}(15)=956.78^{* *}$ \\
\hline
\end{tabular}

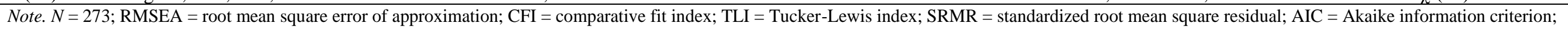
$\mathrm{BIC}=$ Bayesian information criterion; FS = feedback seeking; ATI = individual task adaptivity; WB = well-being involvement; WD = withdrawal; POO = perceived organizational obstruction. ${ }^{\mathrm{a}}$ cutoff value.

$* * p<.01$. 
FROM FEEDBACK SEEKING TO PSYCHOLOGICAL ATTACHMENT

Table 2.

Mean, Standard Deviation and Correlation among Variables

\begin{tabular}{lccccccccccc}
\hline & $M$ & $S D$ & 1 & 2 & 3 & 4 & 5 & 6 & 7 & 8 & 9 \\
\hline 1. Age & - & - & - & & & & & & & & \\
2. Job tenure & - & - & $.59^{* *}$ & - & & & & & & \\
3. Private vs. public & - & - & -.00 & -.06 & - & & & & & \\
4. Sector activity & - & - & $.17^{*}$ & -.01 & $-.15^{*}$ & - & & & & \\
5. Feedback seeking & 3.38 & .79 & -.06 & $-.14^{*}$ & -.01 & $-.15^{*}$ & $(.81)$ & & & \\
6. Individual task adaptivity & 3.67 & .70 & -.03 & $-.12^{*}$ & .01 & -.07 & $.28^{* *}$ & $(.69)$ & & & \\
7. Well-being involvement & 3.65 & .86 & .05 & .08 & -.03 & .07 & $.13^{*}$ & $.25^{* *}$ & $(.87)$ & & \\
8. Withdrawal & 1.66 & .61 & .11 & .10 & .01 & -.10 & .00 & $-.18^{* *}$ & $-.13^{*}$ & $(.74)$ & \\
9. Perceived organizational obstruction & 2.30 & 1.09 & .00 & .06 & -.02 & .00 & $-.13^{*}$ & $-.13^{*}$ & $-.62^{* *}$ & $.18^{* *}$ & $(.95)$ \\
\hline
\end{tabular}

Note. $N=273$; The Omega scores corresponds to the number in brackets.

$* p<.05 . * * p<.01$. 
FROM FEEDBACK SEEKING TO PSYCHOLOGICAL ATTACHMENT

Table 3.

Analyses of the Mediation Model and Indirect Path Results

\begin{tabular}{|c|c|c|c|c|c|c|c|c|c|c|c|c|}
\hline & \multicolumn{6}{|c|}{ Model 1} & \multicolumn{6}{|c|}{ Model 2} \\
\hline & $\begin{array}{c}\text { Individual } \\
\text { task } \\
\text { adaptivity }\end{array}$ & $95 \% \mathrm{CI}$ & $\begin{array}{l}\text { Well-being } \\
\text { involvement }\end{array}$ & $95 \% \mathrm{CI}$ & Withdrawal & $95 \% \mathrm{CI}$ & $\begin{array}{c}\text { Individual } \\
\text { task } \\
\text { adaptivity }\end{array}$ & $95 \% \mathrm{CI}$ & $\begin{array}{l}\text { Well-being } \\
\text { involvement }\end{array}$ & $95 \% \mathrm{CI}$ & Withdrawal & $95 \% \mathrm{CI}$ \\
\hline \multicolumn{13}{|l|}{ Control Variables } \\
\hline Age & .01 & {$[-.11, .13]$} & -.05 & {$[-.19, .08]$} & .07 & {$[-.04, .18]$} & .03 & {$[-.21, .27]$} & -.15 & {$[-.41, .10]$} & .16 & {$[-.07, .40]$} \\
\hline Tenure & -.05 & {$[-.16, .05]$} & $.15^{*}$ & {$[.01, .29]$} & .00 & {$[-.09, .10]$} & -.10 & {$[-.32, .12]$} & $.37 * *$ & {$[.10, .65]$} & .02 & {$[-.20, .24]$} \\
\hline Private $v s$ public & -.00 & {$[-.20, .20]$} & .02 & {$[-.17, .23]$} & .00 & {$[-.17, .18]$} & -.01 & {$[-.45, .42]$} & -.00 & {$[-.41, .40]$} & .04 & {$[-.34, .43]$} \\
\hline Sector & -.01 & [-.08. .05] & .05 & {$[-.02, .13]$} & -.06 & {$[-.12, .00]$} & -.02 & {$[-.17, .12]$} & .10 & {$[-.05, .26]$} & -.10 & {$[-.24, .03]$} \\
\hline \multicolumn{13}{|l|}{ Path Model } \\
\hline Feedback seeking & $.32 * *$ & {$[.15, .50]$} & -.02 & {$[-.20, .14]$} & .13 & {$[-.03, .30]$} & $.43 * *$ & {$[.20, .66]$} & -.13 & {$[.39, .13]$} & .22 & {$[-.04, .49]$} \\
\hline $\begin{array}{l}\text { Individual task } \\
\text { adaptivity }\end{array}$ & - & & $.40^{* *}$ & {$[.18, .78]$} & $-.38 * *$ & {$[-.64,-.13]$} & - & & $.43 * *$ & {$[.17, .70]$} & $-.38^{* *}$ & {$[-.63,-.13]$} \\
\hline POO & - & & - & & - & & - & & $-1.09 * *$ & {$[-1.39,-.78]$} & $.24 *$ & {$[.02, .46]$} \\
\hline POOxATI & - & & - & & - & & - & & $.33 * *$ & {$[.09, .57]$} & $-.24 *$ & {$[-.47,-.02]$} \\
\hline \multicolumn{13}{|l|}{ Indirect path model } \\
\hline Feedback seeking & - & & $.15^{*}$ & {$[.03, .27]$} & $-.12 *$ & {$[-.23,-.02]$} & - & & $.14^{*}$ & {$[.02 ; .26]$} & -.10 & {$[-.22, .00]$} \\
\hline \multicolumn{13}{|c|}{ Conditional indirect effect } \\
\hline Low POO & - & & - & & - & & - & & .04 & {$[-.10, .19]$} & -.05 & {$[-.20, .08]$} \\
\hline Medium POO & - & & - & & - & & - & & $.19 *$ & {$[.04, .34]$} & $-.16^{*}$ & {$[-.30,-.03]$} \\
\hline High POO & - & & - & & - & & - & & $.33 * *$ & {$[.10, .56]$} & $-.27 * *$ & {$[-.48,-.07]$} \\
\hline$R$ square & $.16^{*}$ & & $.15^{*}$ & & $.13^{*}$ & & $.16^{*}$ & & $.60 * *$ & & $.21 *$ & \\
\hline
\end{tabular}

$R$ square

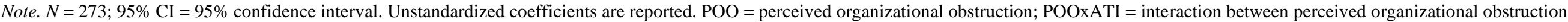
and individual task adaptivity.

$* p<.05 . * * p<.01$. 


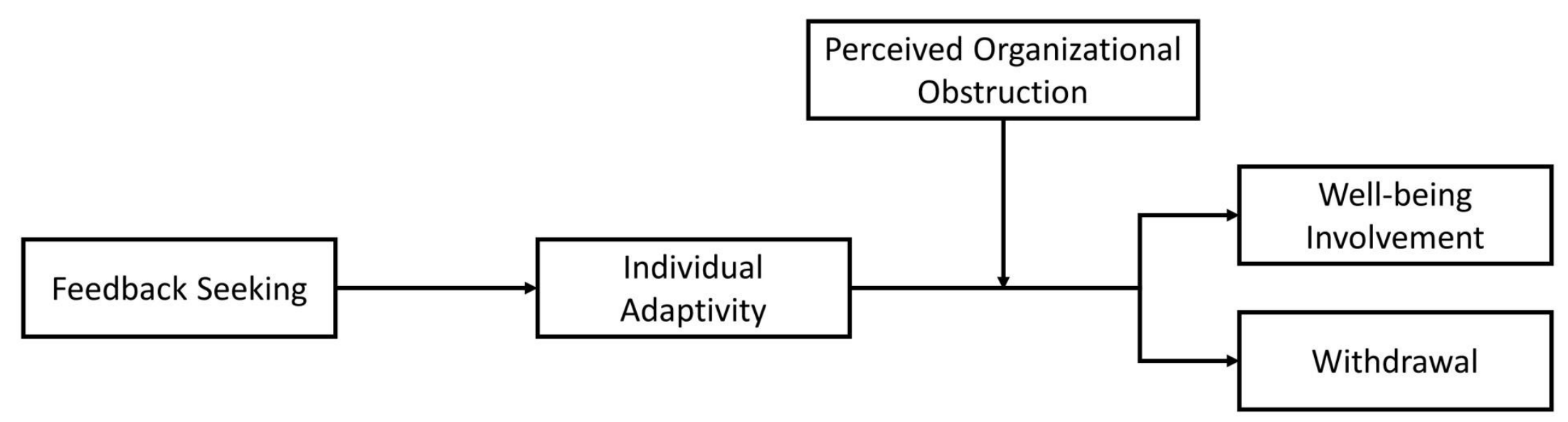




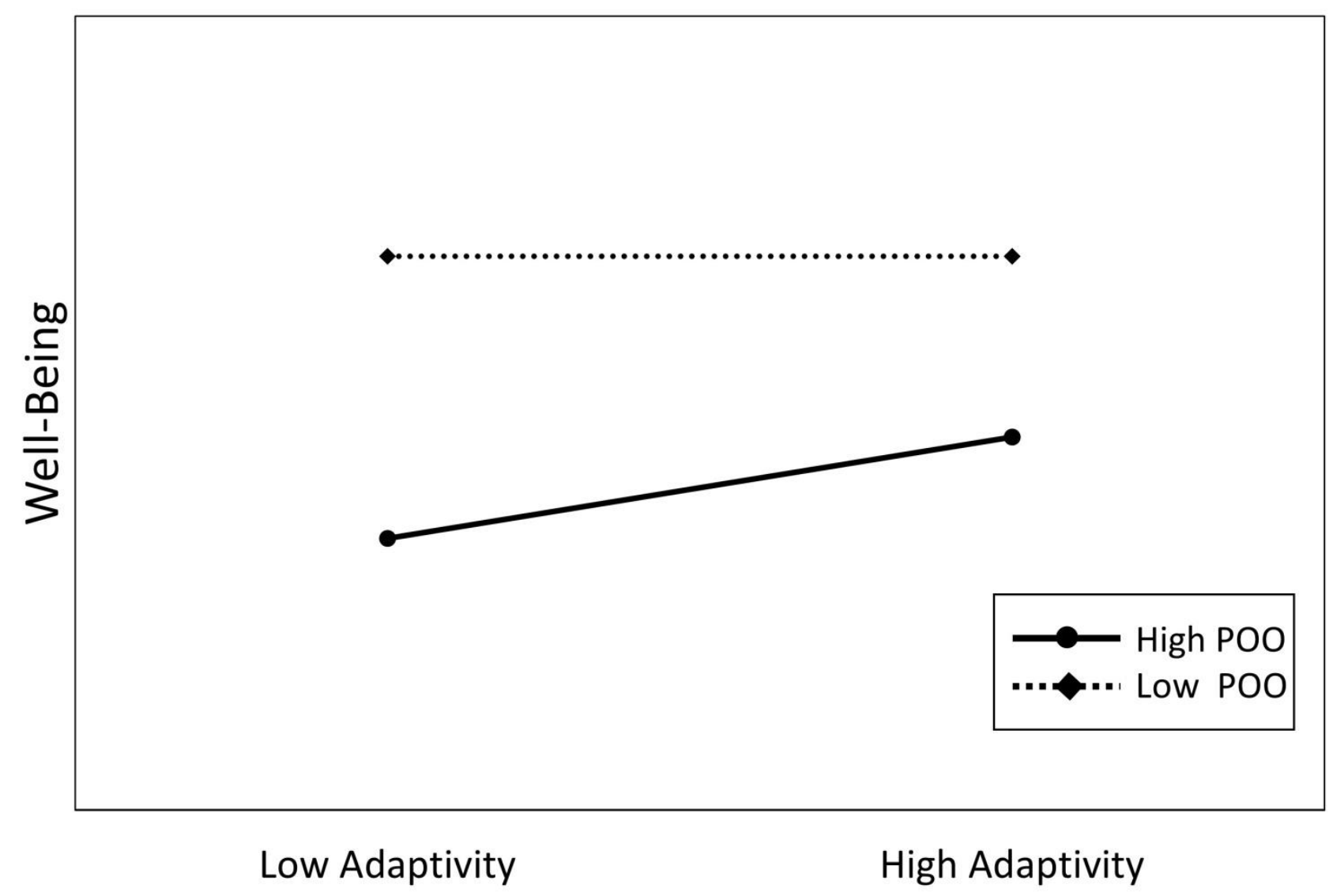




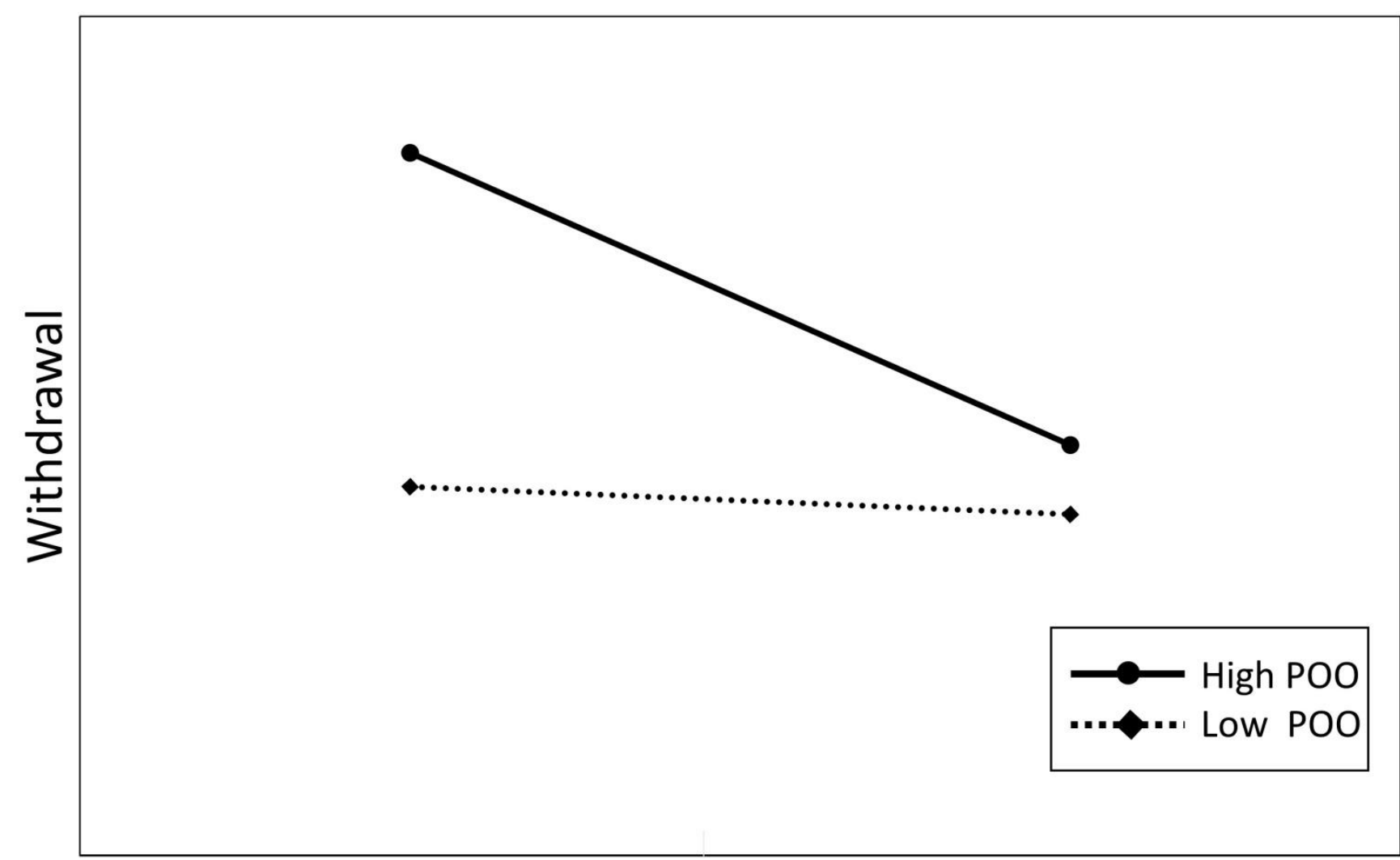

Low Adaptivity

High Adaptivity 